mannered that an occasional demonstration of individuality is forgivable.

The decision to omit such internal geographical subdivisions as Mysia, Pisidia and Lycaonia will not be regretted, for this classical hangover was always some. thing of a burden on our memories and a cause of confusion. It would, however, be useful to have some general indication of distribution within Turkey, apart from the grid and vilayet references, and it is to be hoped that some acceptable system will be devised in time for the next volume.

R. D. MeikLe

\section{DESIGN IN FISHES}

\section{Functional Design in Fishes}

By R. McN. Alexander. (Hutchinson University Library.) Pp. 160. (London: Hutchinson and Co. (Publishers), Ltd., 1967.) 10s. 6d. paper.

THIs book is about the structure of fishes. The functional design, as shown by the anatomical and physiological characteristics selected by the author, is related to evolution by natural selection. Where appropriate the author supports his arguments with mathematics and physics, but, wisely, he warns the student that the subject must be approached in the manner of historians and critics. Mathematics and physics do not render the conclusions unassailable, because in any biological situation there are so many interacting structures and functions that there is always a danger of overlooking an important point.

The first chapter is about the coefficient of selection. The author examines the case of a genotype which increases the amount of food a fish obtains, or decreases energy consumption, thereby tending to increase the number of eggs laid by females, and being favoured by selection. He concludes that evolution by natural selection offers a plausible explanation for adaptations which result in small savings of energy.

The next five chapters deal with swimming, buoyancy, respiration, feeding and some sense organs. In each of these chapters analyses of the structures and functions of the organ systems are made, and related to the natural history of the fishes discussed.

A final chapter is concerned with the interactions between different functions or consequences of a single structure. This chapter is a most important one, because of the danger of oversimplification in a mathematical and physical analysis of a biological complex. It is so important that it should have been at the beginning rather than at the end of the book.

An appendix gives an outline classification of the fishes. It goes down to the level of orders, except in the case of the Cypriniformes and Perciformes, where some suborders are given. This brief systematic section is useful for students.

The reference list gives seven books on fishes, and there are eighty-eight other references, not representing an exhaustive bibliography, but serving as an entry into the literature of the subject.

There are sixteen clearly drawn figures. A highly com. mendable feature of the book is the complete relevance and full discussion of these figures in the text.

The book is a good introduction to the concept of functional design in fishes. It will be helpful to undergraduate students, for whom the series of books is intended. It will also be useful to workers in other fields of biology because it is a lucid and concise account.

One fault must be noted. Throughout the book the fish are called by their generic names only. This procedure is adopted even when it is clear that one species is meant and not all representatives of the genus. It is surprising that such nomenclatural inexactitude should occur, and it is to be hoped that this will be corrected in subsequent editions.

\section{SOIL BIODYNAMICS MISMANAGED}

\section{Soil Fertility}

A Biodynamical Approach. By F. W. Pauli. Pp. xi +204. (London: Adam Hilger, Ltd., 1967.) 50s. net.

THE idea of the soil as a biologically active environment is well accepted. The relationships between plants and soil conditions continue to provide fascinating studies and we still have much to learn, In the preface to this book Professor Flaig draws our attention to the fact that recent emphasis on inorganic ions for plant nutrition has led to neglect of work on humus. Paradoxically, soil organic matter is most studied in countries using most mineral fertilizers. Dr Pauli aims to remedy the shortcomings of work with fertilizers by considering the soil ecosystem as a whole and relating the results of research on soil organic matter using modern analytical techniques to the problems of improving soil fertility measured by increased crop production. If this aim is achieved, then, as Dr Pauli hopes, some profitable new approaches to problems in soil fertility should develop. Unfortunately, he fails in his effort and what is worse sometimes confuses his interpretation of present knowledge. We shall have to wait longer for the inspired synthetical approach the subject demands.

The book is divided into seven chapters of text varying in length from three to seventy-three pages. Following four short introductory chapters, most of the text is in the fifth chapter on humus and soil fertility (59 pages), the sixth chapter on analytical techniques (73 pages) and the seventh chapter on man's exploitation of soil biodynamics (19 pages). There are two pages of conclusions and a glossary, bibliography and index.

The book is written without references inserted in the text so that the reader does not know either to whom to attribute the various statements or how much of the book represents published work and how much is interpretation by the author. The list of books, theses and papers provides no clue. The author states that his bibliography does not claim to be exhaustive and he does not indicate his method of selection. The bibliography does not contain several books one might expect to find, and references to published work by several established workers are missing from the list of papers.

Dr Pauli omits the role of fungi in the breakdown of plant material and the synthesis of humus. Normally, in aerobic soils the initial attack is by fungi, and subsequent decomposition by fungi and/or bacteria depending on the soil conditions. In anaerobic soils, plant remains are decomposed only by bacteria with the accumulation of lignified residues as peat. Terminology is bad throughout; for example, Dr Pauli writes of "low-molecular humus" when presumably he means "humus of low-molecular weight compounds".

On page 35, he describes clay minerals, "Many of the clay minerals consist of cations co-ordinated with water, $\mathrm{OH}^{-}, \mathrm{O}^{--}$and other anions, some of which are excellent bridging ligands and give rise to amorphous and crystalline solid particles. The crystalline particles show disorder and other imperfections, and may have amorphous coatings. The large surfaces contain many groups, among which are oxygen and different kinds of hydroxyl groups which may dissociate, yielding negatively and positively charged surfaces. In addition, electrical charges arise as a result of ionic substitution inside the lattice." Dr Pauli's basic description of the structure of a clay mineral differs so much from the accepted idea of layer structures of clay minerals derived basically from two units $(a)$ of four oxygens at the corners of a tetrahedron with a silicon ion in the centre, and $(b)$ of six oxygens or hydroxyls at the corners of an octahedron with typically an aluminium or magnesium ion at the centre, and with charges arising within the crystal from isomorphous replacement and at the edges of crystals by discontinuity, that one wonders at the source of his description and his interpretation. 